\section{Changes in synovitis and bone marrow lesions may not mediate the effect of cartilage loss on joint pain in osteoarthritis}

We read with interest the recent article by Bacon $e t a l^{1}$ that used mediation analysis ${ }^{2}$ to understand the process by which cartilage loss changes joint pain. Given considerable investment in treatments that focus on chondroprotection, this is an important topic and the findings from this study have potential to inform patient management. The authors concluded that a small, nonclinically important effect of cartilage loss on joint pain was mediated by synovitis. To ensure this study accurately informs future research and practice, we ask the authors to clarify the reporting and interpretation of their results.

The results presented in tables 3 and 4 do not support the authors conclusion that synovitis mediated the effect of cartilage loss on joint pain. The 95\% CIs for all of the indirect effects presented include the null. If correct, these indirect effects and their precision estimates clearly demonstrate that in this study, there was no evidence that synovitis and bone marrow lesions mediate the effect of cartilage loss on joint pain. We suspect the authors might have used the 'proportion mediated' estimates to draw their conclusions. However, in most settings, the indirect effect estimate is a more robust measure than the proportion mediated. ${ }^{3}$ Although the proportion mediated is intuitive for interpretation, it is subject to a number of limitations. ${ }^{4}$ For example, the proportion mediated is considered to be highly variable, particularly with small sample sizes and uncertain indirect and direct effect estimates. ${ }^{5}$ Therefore, the main conclusions of the study should primarily reflect the indirect effect, rather than the proportion mediated. We urge the authors to consider this and revise their conclusions appropriately.

We also have some concerns about the accuracy of the numbers presented in tables 3 and 4 . The point estimates of the proportion mediated for synovitis are identical for both exposures $(0.1$ and $0.05 \mathrm{~mm}$ cartilage thickness loss) despite differences in their indirect and total effect estimates. If we assume that the proportion mediated is simply the ratio of the indirect effect and the total effect, on the difference scale, ${ }^{6}$ the proportion mediated should be $15.1 \%$ for $0.1 \mathrm{~mm}$ and $12.5 \%$ for $0.05 \mathrm{~mm}$ in table 3 , and $25.0 \%$ for $0.1 \mathrm{~mm}$ and $20.0 \%$ for $0.05 \mathrm{~mm}$ in table 4 . It would be helpful if the authors could verify these estimates or clearly state how the proportion mediated was estimated if they used a different method.

Finally, when mediators fail to explain a mechanism, the path specific exposure-mediator and mediator-outcome effects can be informative for explaining where the indirect effect broke down. ${ }^{3}$ In Bacon's study, cartilage thickness may not be associated with synovitis or bone marrow lesions, or these mediators may not be associated with the outcome joint pain, or both. We encourage the authors to consider reporting these path specific effects to provide readers with a better understanding for why cartilage loss does not have an effect on joint pain via synovitis and bone marrow lesions.

Aidan G Cashin $\odot$, 1,2 James H McAuley $\odot,^{1,3}$ Hopin Lee $\odot{ }^{4,5}$

${ }^{1}$ Centre for Pain IMPACT, Neuroscience Research Australia, Randwick, New South Wales, Australia

2Prince of Wales Clinical School, Faculty of Medicine, University of New South Wales, Sydney, New South Wales, Australia

${ }^{3}$ School of Medical Sciences, Faculty of Medicine, University of New South Wales, Sydney, New South Wales, Australia

${ }^{4}$ Centre for Statistics in Medicine \& Rehabilitation Research in Oxford, Nuffield Department of Orthopaedics Rheumatology and Musculoskeletal Sciences (NDORMS), University of Oxford, Oxford, UK

${ }^{5}$ School of Medicine and Public Health, The University of Newcastle, Callaghan, New South Wales, Australia

Correspondence to Aidan G Cashin, Centre for Pain IMPACT, Neuroscience Research Australia, Randwick, NSW 2031, Australia; a.cashin@neura.edu.au

Twitter Aidan G Cashin @AidanCashin, James H McAuley @Pain_NeuRa and Hopin Lee @hopinlee

Contributors All authors contributed to the concept, design and writing of the letter and have approved the final version.

Funding AGC is supported by the University of New South Wales Prince of Wales Clinical School Postgraduate Research Scholarship and a NeuRA PhD Candidature Supplementary Scholarship. HL is supported by a National Health and Medical Research Council research fellowship and by the National Institute for Health Research (NIHR) Collaboration for Leadership in Applied Health Research and Care Oxford at Oxford Health NHS Foundation Trust.

Competing interests None declared.

Patient and public involvement Patients and/or the public were not involved in the design, or conduct, or reporting, or dissemination plans of this research.

Patient consent for publication Not required.

Provenance and peer review Not commissioned; internally peer reviewed.

(c) Author(s) (or their employer(s)) 2020. No commercial re-use. See rights and permissions. Published by BMJ.

\section{Check for updates}

To cite Cashin AG, McAuley JH, Lee H. Ann Rheum Dis Epub ahead of print: [please include Day Month Year]. doi:10.1136/annrheumdis-2020-218139

Received 28 May 2020

Accepted 31 May 2020

Ann Rheum Dis 2020;0:1. doi:10.1136/annrheumdis-2020-218139

\section{ORCID iDs}

Aidan G Cashin http://orcid.org/0000-0003-4190-7912

James H McAuley http://orcid.org/0000-0002-0550-828X

Hopin Lee http://orcid.org/0000-0001-5692-0314

\section{REFERENCES}

1 Bacon K, LaValley MP, Jafarzadeh SR, et al. Does cartilage loss cause pain in osteoarthritis and if so, how much? Ann Rheum Dis 2020. doi:10.1136/ annrheumdis-2020-217363. [Epub ahead of print: 7 May 2020].

2 Lee H, Herbert RD, McAuley JH. Mediation analysis.. JAMA 2019;321:697-8.

3 VanderWeele T. Explanation in causal inference. Oxford University Press, 2015.

4 MacKinnon DP, Fairchild AJ, Fritz MS. Mediation analysis.. Annu Rev Psychol 2007;58:593-614

5 Mackinnon DP, Warsi G, Dwyer JH. A simulation study of mediated effect measures. Multivariate Behav Res 1995;30:41-62.

6 VanderWeele TJ. Policy-relevant proportions for direct effects. Epidemiology 2013;24:175-6. 